\title{
Synthesis and structural characterization of CsNiP crystal
}

\author{
G S GOPALAKRISHNA*, B H DORESWAMY ${ }^{\dagger}$, M J MAHESH, M MAHENDRA ${ }^{\dagger}$, \\ M A SRIDHAR ${ }^{\dagger}$, J SHASHIDHARA PRASAD ${ }^{\dagger}$ and $\mathrm{K}$ G ASHAMANJARI
}

Department of Studies in Geology, 'Department of Studies in Physics, University of Mysore, Manasagangotri, Mysore 570 006, India

MS received 21 August 2003

\begin{abstract}
CsNiP crystals were synthesized by hydrothermal technique and characterized by the X-ray diffraction method. This alkaline transition metal phosphide crystallizes in the hexagonal system with space group $P 6_{3} / m m c$ and cell parameters, $a=7 \cdot 173(2) \AA, c=5 \cdot 944(9) \AA, V=264 \cdot 87(7) \AA^{3}$ and $Z=2$. The final residual factor is $R 1=0.0362$ for 206 reflections with $I>2 \sigma(I)$.
\end{abstract}

Keywords. Phosphides; hydrothermal; crystal structure; FTIR; DTA.

\section{Introduction}

Synthetic alkaline metal phosphide derivatives were reported for the first time in the later part of fifties and early part of sixties (Issleib and Tzschach et al 1959; Fluck and Issleib 1965). However, studies of these alkaline metal phosphides gained momentum since last three decades (Johnson and Jeitschlo 1972; Barz et al 1983; Muller et al 1983; Schnering et al 1999). In recent years, structural data of phosphides also were reported (Shannon 1976; Jeitschlo and Braun 1977; Braun and Jeitschlo 1980a, b; Nakotte et al 1999; Sekine et al 1999; Rabe et al 2000). The alkaline metal phosphides are good diamagnetic semiconductors (Ackernann and Wold 1977; Danebrock et al 1996; Shirotani et al 1996; Kuriyama et al 1998) and also show superconductivity at low temperature (Sakon et al 1999; Shirotani et al 2000). Here, we report a new material of mono $\mathrm{CsNiP}$ derivative in the form of a single crystal exhibiting paramagnetic properties.

\section{Experimental}

CsNiP crystals were synthesized by the hydrothermal method. The growth of phosphides by the hydrothermal technique is relatively new and the use of hydrothermal method is quite complicated for these compounds because of the highly corrosive and volatile nature of phosphorus at higher temperature. The present experiments were carried out in Morey type autoclaves provided with Teflon liners, at the temperature and pressure of $260^{\circ} \mathrm{C}$ and 100 bars (Byrappa et al 1985). The crystallization was carried out by spontaneous nucleation controlled through a slow and programmed rate of heating. The starting mate-

\footnotetext{
*Author for correspondence
}

rial such as chloride or nickel was taken in a Teflon liner and $85 \% \mathrm{H}_{3} \mathrm{PO}_{4}$ was poured into it. The alkaline component of the starting material was taken in the form of molar solutions having a definite molarity. CsNiP crystals were synthesized under the following conditions: Molar ratio $=\mathrm{Cs}_{2} \mathrm{O}: \mathrm{Ni}_{2} \mathrm{O}_{3}: \mathrm{P}_{2} \mathrm{O}_{5}, 3-4: 1-1 \cdot 5: 10-12, T=260^{\circ} \mathrm{C} ; P=$ 100 bars; duration $=8-10$ days.

The following reaction could explain the formation of CsNiP

$$
\mathrm{CsCl}+\mathrm{NiCl}_{2}+\mathrm{H}_{3} \mathrm{PO}_{4} \rightarrow \mathrm{CsNiP}+\uparrow 3 \mathrm{HCl}+\uparrow 2 \mathrm{O}_{2} .
$$

The crystals obtained by this method were of good quality exhibiting translucent luster having well developed morphology. The size of crystals ranged from $0 \cdot 5-2 \mathrm{~mm}$ with pinkish yellow colour.

A single crystal of $\mathrm{CsNiP}$ of dimension $0.3 \times 0.2 \times$ $0 \cdot 25 \mathrm{~mm}$ was used for X-ray diffraction study. The measurements were made on a DIPLabo Imaging Plate system with graphite monochromated radiation $\left(\mathrm{MoK}_{\alpha}\right)$. Thirty six frames of data were collected by oscillation method. Successive frames were scanned in steps of $5 \% \mathrm{~min}$ with an oscillation range of $5^{\circ}$. Image processing and data reduction were done using Denzo (Otwinowski and Minor 1997; Mackay et al 1999). All frames could be indexed with a hexagonal primitive lattice. The phase set with the highest combined figure of merit gave the positions of all the nonhydrogen atoms. Least-squares refinement using SHELXL97 (Sheldrick 1997) with isotropic temperature factors for all the non-hydrogen atoms converged the residual $R 1$ to 0.0923. Anisotropic refinement was started at this stage and $R 1$ finally converged to $0 \cdot 0362$. The details of crystal data and refinement are given in table 1.

\section{Results and discussion}

The study of morphology of a crystal is important due to its application in device potential. Generally the crystals 
obtained by the hydrothermal method are of good quality and exhibit well developed morphology with smooth surface and translucent luster. The SEM studies of CsNiP crystal show fibrous nature; rod shaped habit with relatively smooth surface (figure 1).

The final positional coordinates with equivalent isotropic temperature factors and anisotropic thermal parameters $\left(U_{i j}\right)$ of all the atoms are listed in tables 2 and 3, respectively. Selected bond distances and angles are given in table 3 . The bond distances and angles are in good agree-

Table 1. X-ray crystallographic details.

\begin{tabular}{ll}
\hline Empirical formula & Cs Ni P \\
Formula weight & $222 \cdot 59$ \\
Temperature & $293(2) \mathrm{K}$ \\
Wavelength & $0 \cdot 71069 \AA$ \\
Crystal colour, habit & Transparent, rectangular \\
Crystal system & Hexagonal \\
Space group & $P 6_{3} / m m c$ \\
Cell dimensions & $a=7 \cdot 173(2) \AA$ \\
& $c=5 \cdot 944(9) \AA$ \\
Volume & $264 \cdot 87(7) \AA^{3}$ \\
$Z$ & 2 \\
Density(calculated) & $2 \cdot 791 \mathrm{mg} / \mathrm{m}^{3}$ \\
Absorption coefficient & $10 \cdot 541 \mathrm{~mm}^{-1}$ \\
$F_{\text {000 }}$ & 196 \\
Crystal size & $0 \cdot 3 \times 0 \cdot 2 \times 0 \cdot 25 \mathrm{~mm}$ \\
Theta range for data collection & $3 \cdot 28^{\circ}$ to $32 \cdot 31^{\circ}$ \\
Index ranges & $0 \leq h \leq 9$ \\
& $0 \leq k \leq 9$ \\
Reflections collected & $-8 \leq l \leq 8$ \\
Independent reflections & 764 \\
Refinement method & $206[R(\mathrm{int})=0 \cdot 1089]$ \\
Data/restraints/parameters & Full-matrix least-squares on $F^{2}$ \\
Goodness-of-fit on $F^{2}$ & $206 / 0 / 10$ \\
Final $R$ indices $[I>2 \sigma(I)]$ & $1 \cdot 298$ \\
$R$ indices (all data) & $R 1=0 \cdot 0362, w R 2=0 \cdot 1079$ \\
Extinction coefficient & $R 1=0 \cdot 0366, w R 2=0 \cdot 1084$ \\
(Shift/e.s.d.) max & $0 \cdot 096(13)$ \\
Largest diff. peak and hole & $0 \cdot 000$ \\
\hline
\end{tabular}

Table 2. Atomic coordinates and equivalent thermal parameters.

\begin{tabular}{lllrc}
\hline Atom & \multicolumn{1}{c}{$x$} & \multicolumn{1}{c}{$y$} & \multicolumn{1}{c}{$z$} & \multicolumn{1}{c}{$U_{\text {eq }}$} \\
\hline Cs1 & 0.3333 & 0.6667 & 0.2500 & $0.0273(4)$ \\
Ni1 & $0 \cdot 0000$ & $1 \cdot 0000$ & 0.0000 & $0 \cdot 0172(4)$ \\
P1 & $0 \cdot 15337(13)$ & $0.84663(13)$ & -0.2500 & $0.0160(4)$ \\
\hline
\end{tabular}

ment with the standard values. Figure 2 represents the ORTEP (Johnson 1976) of the molecules with thermal ellipsoids at $50 \%$ probability. All the three atoms are at special positions. $\mathrm{Ni}$ atom lies on six-fold axis with six phosphorous atoms at their symmetry equivalent positions. The molecular packing along the axes exhibit channel type framework structure having $\mathrm{Cs}$ atoms inside it (figures 3 and 4). This helps for tunnelling of Cs atoms through the channels (Mahendra et al 2003).

FTIR-spectrum was recorded using a high resolution Perkin Elmer Infrared Spectrophotometer in the range $4000-400 \mathrm{~cm}^{-1}$ (figure 5). The spectrum exhibits prominent multiple absorption bands, especially in the range 2922 $1377 \cdot 1 \mathrm{~cm}^{-1}$. The broadness at the 1635 and $651.9 \mathrm{~cm}^{-1}$

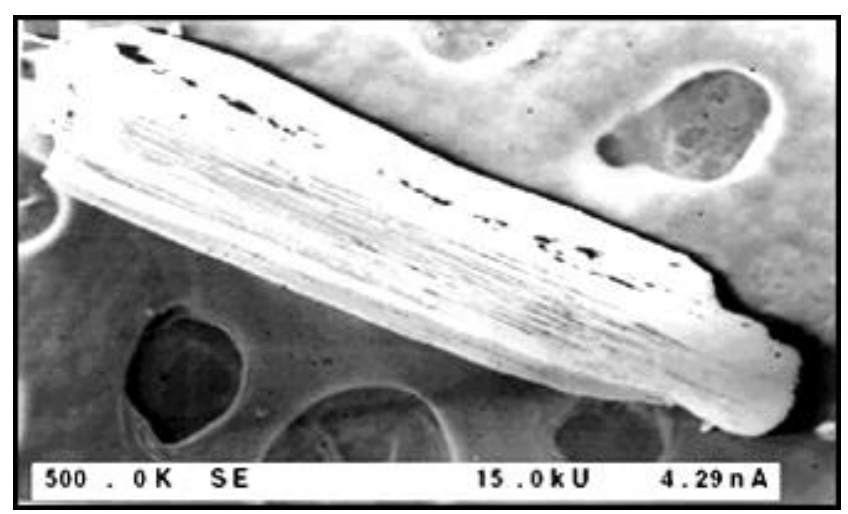

Figure 1. SEM photograph.

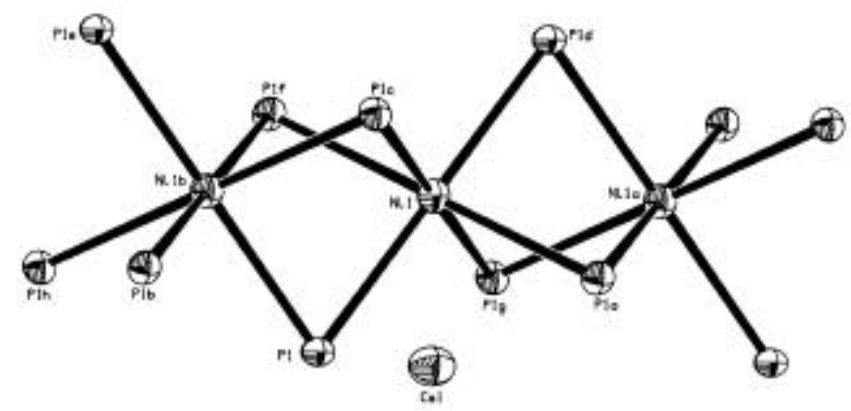

Figure 2. Perspective diagram of the molecule with thermal ellipsoids at $50 \%$ probability [Symmetry codes: $a=(x-y, x$, $-1 / 2+z), b=(x-y, x, 1 / 2+z), c=(-y, x-y, z), d=(-x,-y$, $-1 / 2+z), e=(-x,-y, 1 / 2+z), f=(-x+y,-x, z), g=(y$, $-x+y,-1 / 2+z)$ and $h=(y,-x+y, 1 / 2+z)]$.

Table 3. Anisotropic thermal parameters.

\begin{tabular}{lcccccc}
\hline Atom & $U_{11}$ & $U_{22}$ & $U_{33}$ & $U_{12}$ & $U_{13}$ & $U_{23}$ \\
\hline Cs1 & $0 \cdot 0228(4)$ & $0 \cdot 0228(4)$ & $0 \cdot 0364(6)$ & $0 \cdot 0114(2)$ & $0 \cdot 000$ & $0 \cdot 000$ \\
Ni1 & $0 \cdot 0176(5)$ & $0 \cdot 0176(5)$ & $0 \cdot 0162(7)$ & $0 \cdot 0088(3)$ & $0 \cdot 000$ & $0 \cdot 000$ \\
P1 & $0 \cdot 0172(6)$ & $0 \cdot 0172(6)$ & $0 \cdot 0170(8)$ & $0 \cdot 0113(6)$ & $0 \cdot 000$ & $0 \cdot 000$ \\
\hline
\end{tabular}


indicate the phosphide nature of the compound unlike pyrophosphates (Gopalakrishna et al 2001).

The DTA curve was recorded using DTA/ETA Model 021 from room temperature to $500^{\circ} \mathrm{C}$. $\mathrm{CsNiP}$ shows multiple phase transitions at 150,283 and $384^{\circ} \mathrm{C}$, respectively (figure 6), indicating that this compound has relatively low thermal stability compared to the phosphates (Mahendra et al 2003).

Magnetic measurements were done using Gouy's balance method for the determination of magnetic susceptibility in the magnetic field strength ranging from $0.5-2.5 \mathrm{~K}$
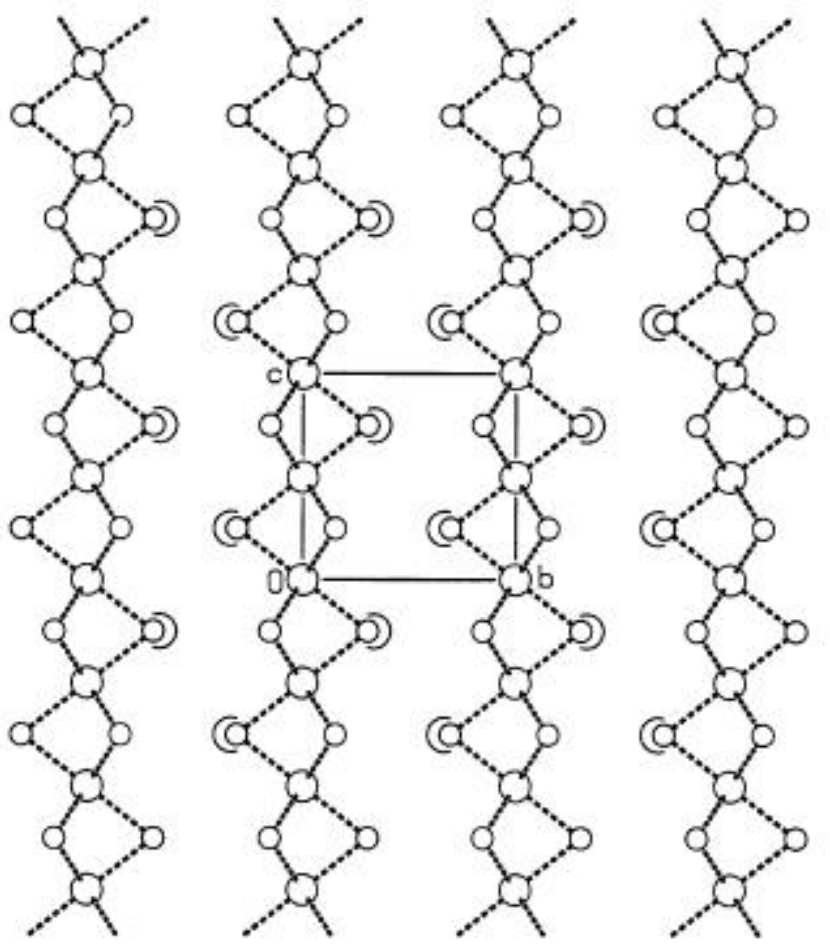

Figure 3. Packing of the molecule down $a$ axis.

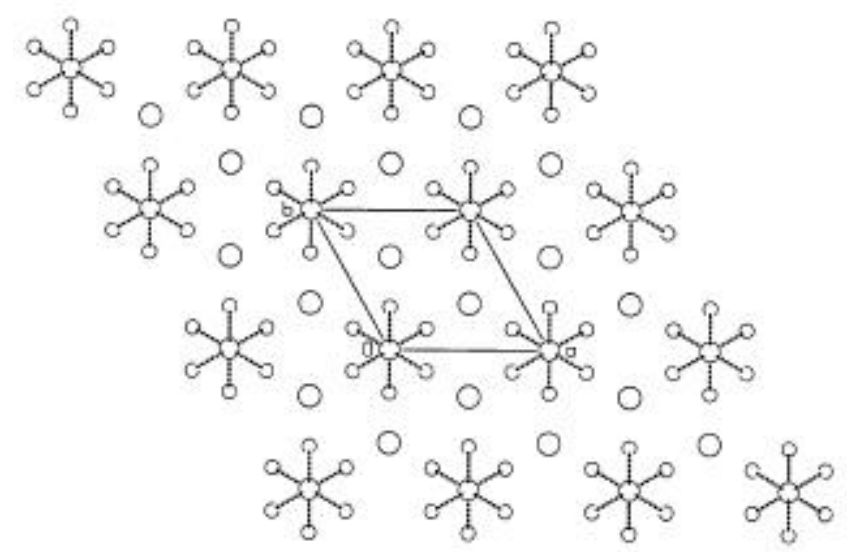

Figure 4. Packing of the molecule down $c$ axis. gauss at $300^{\circ} \mathrm{K}$. Magnetic moments of nickel compounds fall into two broad classes. First, those having essentially temperature independent magnetic moments due to mononuclear complexes having interaction between the unpaired electrons on different nickel ions in the range 2.9-3.9 BM. Second, moments are below the spin only value and temperature dependent. The present compound exhibits magnetic moments in the range $2 \cdot 17-2.60 \mathrm{BM}$ at magnetic field strength $0 \cdot 5-2.5 \mathrm{~K}$ gauss indicating that this CsNiP compound is temperature dependent. Detailed investigations are discussed elsewhere (Martin et al 1996; Shirotani et al 1996; Sakon et al 1999).

\section{Conclusions}

Mono cesium nickel-phosphide compound was synthesized by hydrothermal method in the form of single crystal. $\mathrm{X}$-ray studies revealed that this compound crystallized in hexagonal system with space group $P 6_{3} / m m c$ and exhibits

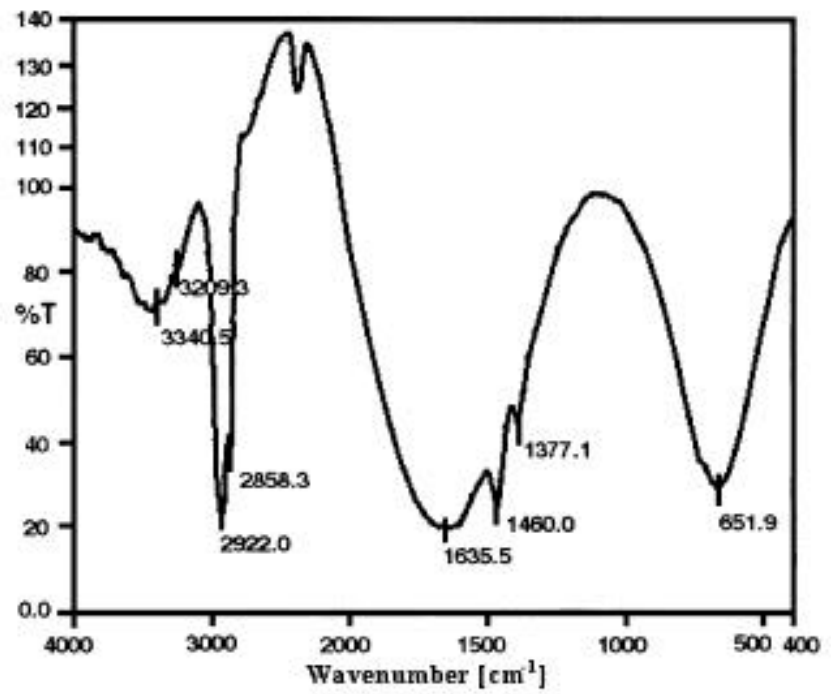

Figure 5. FTIR spectrum.

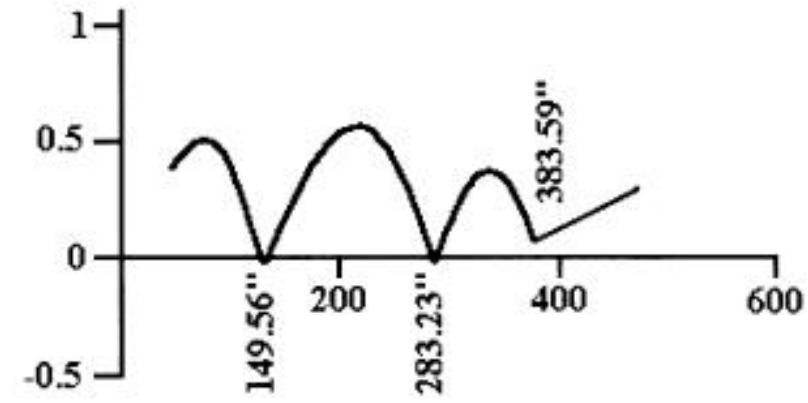

Figure 6. DTA curve. 
Table 4. Bond lengths $(\AA)$ and angles $\left({ }^{\circ}\right)$.

\begin{tabular}{|c|c|c|c|}
\hline Atoms & Length & Atoms & Length \\
\hline $\mathrm{Cs}(1)-\mathrm{P}(1) \# 1$ & $3 \cdot 5904(4)$ & $\mathrm{Ni}(1)-\mathrm{Ni}(1) \# 4$ & $2 \cdot 9719(5)$ \\
\hline Cs(1)-P(1)\#4 & $3 \cdot 5905(8)$ & $\mathrm{P}(1)-\mathrm{Cs}(1) \# 1$ & $3 \cdot 5904(5)$ \\
\hline $\mathrm{Cs}(1)-\mathrm{P}(1) \# 9$ & $3 \cdot 7191(1)$ & $\mathrm{P}(1)-\mathrm{Cs}(1) \# 6$ & $3 \cdot 5905(4)$ \\
\hline $\mathrm{Ni}(1)-\mathrm{P}(1) \# 2$ & $2 \cdot 4164(1)$ & & \\
\hline Atoms & Angle & Atoms & Angle \\
\hline $\mathrm{P}(1) \# 2-\mathrm{Cs}(1)-\mathrm{P}(1) \# 3$ & $120 \cdot 00(2)$ & $\mathrm{P}(1) \# 4-\mathrm{Cs}(1)-\mathrm{P}(1) \# 10$ & $120 \cdot 42(1)$ \\
\hline $\mathrm{P}(1) \# 3-\mathrm{Cs}(1)-\mathrm{P}(1) \# 4$ & $174 \cdot 73(5)$ & $\mathrm{P}(1) \# 7-\mathrm{Cs}(1)-\mathrm{P}(1) \# 11$ & $145 \cdot 01(2)$ \\
\hline $\mathrm{P}(1) \# 5-\mathrm{Cs}(1)-\mathrm{P}(1) \# 7$ & $120 \cdot 42(7)$ & $\mathrm{P}(1) \# 2-\mathrm{Ni}(1)-\mathrm{P}(1)$ & $93 \cdot 85(4)$ \\
\hline $\mathrm{P}(1) \# 6-\mathrm{Cs}(1)-\mathrm{P}(1) \# 7$ & $91 \cdot 59(2)$ & $\mathrm{P}(1) \# 4-\mathrm{Ni}(1)-\mathrm{Ni}(1) \# 12$ & $127 \cdot 95(2)$ \\
\hline $\mathrm{P}(1) \# 3-\operatorname{Cs}(1)-\mathrm{P}(1) \# 8$ & $91 \cdot 58(2)$ & $\mathrm{Ni}(1)-\mathrm{P}(1)-\mathrm{Cs}(1) \# 1$ & $92 \cdot 08(2)$ \\
\hline $\mathrm{P}(1) \# 7-\operatorname{Cs}(1)-\mathrm{P}(1) \# 8$ & $145 \cdot 01(2)$ & Cs(1)\#1-P(1)-Cs(1)\#6 & $174 \cdot 73(5)$ \\
\hline $\mathrm{P}(1) \# 8-\mathrm{Cs}(1)-\mathrm{P}(1) \# 9$ & $106 \cdot 09(4)$ & $\mathrm{Ni}(1)-\mathrm{P}(1)-\mathrm{Cs}(1) \# 13$ & $164 \cdot 90(4)$ \\
\hline $\mathrm{P}(1) \# 2-\mathrm{Cs}(1)-\mathrm{P}(1) \# 10$ & $91 \cdot 58(2)$ & & \\
\hline
\end{tabular}

[Symmetry transformations used to generate equivalent atoms: \#1 $(-x+1,-y+2,-z)$, \#2 $(x-y+1, x+1,-z), \# 3(y,-x+y, z+1 / 2), \# 4(y-1,-x+y, z+1 / 2), \# 5(x-y+1$, $x,-z), \# 6(-x,-y+1,-z), \# 7(x, y, z+1), \# 8(-y+1, x-y+1,-z-1 / 2), \# 9(-y+1$, $x-y+1,-z+1 / 2), \# 10(-x+y,-x+1, z+1), \# 11(-x+y,-x+1, z), \# 12(y-1$, $-x+y, z-1 / 2)$ and $\# 13(x, y, z-1)]$.

channel type structures. Magnetic measurements indicated that it is a temperature dependent mononuclear compound.

\section{Acknowledgements}

The authors would like to express their thanks to DST, New Delhi, for financial assistance under the projects SP/S2/M-44/96-97 and SP/I2/FOO/93.

\section{References}

Ackernann J and Wold A 1977 J. Phys. Chem. Solids 381013 Barz H, Ku H C, Meisner G P, Fisk Z and Matias B T 1983 Proc. Nat. Acad. Sci. USA 77

Braun D J and Jeitschlo W J 1980a Solid State Chem. 32357

Braun D J and Jeitschlo W J 1980b Less Common Metals 72 147

Byrappa K, Gopalakrishna G S, Venkatachalapathy V and Puttaraju B 1985 J. Mater. Sci. 201419

Danebrock M E, Evers C B H and Jeitschko W 1996 J. Phys. Chem. Solids 57381

Fluck E, Issleib K and Tell B 1965 Naturforsch Z. 201123

Gopalakrishna G S, Prasad J S and Lokanath N K 2001 Proc. joint 4th and 6th ICSTR (eds) Yanagisawa and Qi Feng (Kochi, Japan)

Gopalakrishna G S, Prasad J S, Ashamanjari K G, Mahesh M J and Madhu S P 2003 Ind. Miner. 3757

Issleib K and Tzschach A 1959 Chem. Bar. 921118

Jeitschlo W and Braun D J 1977 Acta Crystallogr. B33 3401

Johnson C K 1976 ORTEP-II. A Fortran Thermal-Ellipsoid Plot
Program. Report ORNL-5138, Oak Ridge National Laboratory, Oak Ridge, Tennessee, USA

Johnson V and Jeitschlo W 1972 J. Solid State Chem. 4123

Kuriyama K, Kushida K and Taguchi R 1988 Solid State Commun. 108429

Mackay S, Gilmore C J, Edwards C, Stewart N and Shankland $\mathrm{K} 1999$ maXus computer program for the solution and refinement of crystal structures (The Netherlands: Bruker Nonius, Japan: MacScience and The University of Glasgow)

Mahendra M, Madhu S P, Doreswamy B H, Gopalakrishna G S, Sridhar M A and Prasad J S 2003 Mater. Res. Bull. 33 1309

Muller R, Shelton R N, Richardson H W and Jacobson R A 1983 J. Less Common Metals 92177

Nakotte H et al 1999 Physica B259-261 280

Otwinowski Z and Minor W 1997 in Methods in enzymology, 276 (eds) C W Carter Jr. and R M Sweet (New York: Academic Press) pp 307-326

Rabe G W, Heise H, Liable-Sands L M, Guzei I A and Rheingold A L 2000 J. Chem. Soc. Dalton Trans. 1863

Sakon T et al 1999 Physica B259-261 300

Schnering H G, Liable-Sands W, Incarvito C D, Lam K C and Rheingold A L 1999 Inorg. Chem. 384342

Sekine C, Saito H, Sakai A and Shiroani I 1999 Solid State Commun. 109449

Shannon R D 1976 Acta Crystallogr. A32 751

Sheldrick G M 1997 SHELXL-97. Program for the refinement of crystal structures (Germany: University of Göttingen)

Shirotani I, Adachi Takafumi, Todo Kenji Sakae, Nozawa Kiyokazu, Yagi Takehiko and Kinoshita Minoru 1996 J. Phys. Chem. Solids 57211

Shirotani I, Takaya M, Kaneko I, Sekine C and Yagi T 2000 Solid State Commun. 116683 